\title{
Virulence of Oat Crown Rust in Brazil and Uruguay
}

K. J. Leonard, U.S. Department of Agriculture, Agricultural Research Service, Cereal Disease Laboratory, University of Minnesota, St. Paul 55108, and J. A. Martinelli, Faculade de Agronomia, UFRGS, C. P. 776, 90012-970 Porto Alegre, RS, Brazil

\begin{abstract}
Leonard, K. J., and Martinelli, J. A. 2005. Virulence of oat crown rust in Brazil and Uruguay. Plant Dis. 89:802-808.

Race-specific resistance to crown rust, the most important disease of oat (Avena sativa) in Brazil, often fails within a few years of use in Brazilian cultivars. Virulence of 144 isolates of Puccinia coronata from cultivated oat in Brazil in 1997 to 1999 and 36 isolates from Uruguay in 1994-95 and 1998 was tested on a set of 27 oat crown rust differentials lines, each with a different $P c$ gene for race-specific resistance. Frequencies of virulence and mean virulence complexity were compared among these five collections from Brazil and Uruguay as well as with mean virulence complexity for a collection of 17 isolates from cultivated oat in western Siberia in Russia. Virulence-avirulence for each of the $27 P c$ genes was polymorphic in both Brazil and Uruguay. Virulence frequencies were similar for collections from Brazil in 1998 and 1999 and for the collection from Uruguay from 1998, but there were large differences between the 1997 collection and the 1998 and 1999 collections from Brazil. Mean virulence complexity in both Brazil and Uruguay was greater than reported in the United States and much greater than in the Russian collection of $P$. coronata. A large number of races of $P$. coronata were found, with no more than five isolates of any race found in a single year in Brazil or Uruguay. The high virulence complexity and great diversity of virulence polymorphisms in Brazil and Uruguay make it unlikely that race-specific resistance can be effective there even though the South American populations of $P$. coronata are apparently entirely asexual.
\end{abstract}

Additional keywords: balancing selection, coevolution

Oat (Avena sativa) is an important forage and grain crop in countries of the southern cone region of South America. Approximately 600,000 ha of oats are grown for grain in Argentina, Uruguay, and southern Brazil. Also, more than 4,000,000 ha are grown for forage $(17,19,22)$, although in Brazil much of the forage oat is A. strigosa rather than A. sativa. In the subtropical to temperate climate of this region, oat is grown in the winter and is used as a winter cover crop, as food for both livestock and humans, and as raw material for industrial uses. It is the third most important winter crop in southern Brazil. Crown rust, caused by Puccinia coronata, is the most important disease of oat in Brazil, Argentina, and Uruguay. Grain yields are negatively correlated with crown rust severity (2) and may be reduced as much as $50 \%$ in susceptible cultivars (16).

Corresponding author: K. J. Leonard

E-mail: kurtl@umn.edu

Current address of K. J. Leonard: Department of Plant Pathology, University of Minnesota, St. Paul 55108.

Accepted for publication 7 March 2005.

DOI: 10.1094/PD-89-0802

This article is in the public domain and not copyrightable. It may be freely reprinted with customary crediting of the source. The American Phytopathological Society, 2005.
Although $P$. coronata produces teliospores, they have no known survival function in South America (15). The primary source of inoculum to infect oat in the fall comes from urediniospores produced on volunteer oat plants that survive the summer at the edges of fields of summer crops such as soybean, in fence rows, and along roadsides. Prevailing wind patterns annually distribute urediniospores of $P$. coronata in a cyclical pattern throughout the oat growing regions of Brazil, Argentina, and Uruguay as a shared epidemiological system. Epidemics typically start early, sometimes while A. sativa is still at the tillering stage of development. A. strigosa is less susceptible than $A$. sativa, but rust severities of 5 to $10 \%$ are common during the crop season. Typically, no chemical control is used for crown rust.

Attempts to breed crown rust resistant oat cultivars in these countries have been frustrated by the buildup of new virulent races of $P$. coronata, often within a few years of the release of cultivars with new types of race-specific resistance. According to Federizzi and Stuthman (5), the rapid breakdown of resistance is due to the large population of $P$. coronata maintained in the uredinial stage throughout the year and the large numbers of mutations to virulence that occur annually in the pathogen population. Although a large number of $P c$ genes for race-specific resistance to crown rust are available to oat breeders, information on occurrence of virulence to these genes in the South American populations of $P$. coronata was largely lacking.

The objectives of this study were (i) to determine the frequencies of virulence to oat lines with known $P c$ genes in collections of $P$. coronata from oat in Brazil and Uruguay in relation to potential effectiveness of breeding oat cultivars for racespecific resistance, and (ii) to compare results in Brazil and Uruguay with virulence diversity found previously in North America. In this study, a collection of oat crown rust isolates from western Siberia in Russia was used as an external reference for comparisons with levels of virulence found in the South American isolates of $P$. coronata.

\section{MATERIALS AND METHODS}

Samples of oat leaves infected with $P$. coronata from Uruguay were provided by S. Pureyra, N. Altier, and M. Rebuffo. All samples from Uruguay were collected from oat cultivars at La Estanzuela, Colonia. Isolates hereafter referred to as the 1994 collection were collected in December 1994 and January 1995. Isolates of the 1998 collection were collected in November. Samples of rusted oat leaves from Brazil were collected from oat cultivars in 1997, 1998, and 1999. Collections in Brazil were made from August to October. The 1997 collection included 25 isolates from Porto Alegre, Rio Grande do Sul; 2 from other sites in Rio Grande do Sul; 21 from Entre Rios, Parana; 5 from other sites in Parana; and 2 from Lages, Santa Catarina. In 1998, all 58 isolates were from nurseries at Porto Alegre. In 1999, 15 isolates were collected in nurseries at Porto Alegre, 11 isolates were collected from other sites in Rio Grande do Sul, and 4 isolates were collected from growers' fields near Entre Rios, Parana. Nine isolates from Rio Grande do Sul in 1999 were collected from growers' fields, six near Passo Fundo, and three near Lagoa Vermelha, and two isolates were collected in a nursery at Vacaria. Isolates of $P$. coronata collected from cultivated oat at Omsk and Altia in western Siberia were provided by J. Holland (then at Iowa State University). All collections were sent to the U.S. Department of Agriculture, Agricultural Research Service, Cereal Disease Laboratory at St. Paul, MN, for virulence tests. Tests were conducted in the greenhouse during the winter months when there were no living hosts in the field in Minnesota and 
there was no chance for $P$. coronata to escape from the greenhouse.

Cyclone spore collectors were used to collect urediniospores from each sample of rusted oat leaves sent to the Cereal Disease Laboratory. Harvested urediniospores were suspended in lightweight mineral oil and used to inoculate 7- to 9-day-old seedlings of the oat cultivar Marvellous, which is susceptible to all known races of $P$. coronata. The seedlings were sprayed with the spore suspension, left for $30 \mathrm{~min}$ to allow the oil to evaporate, and then placed overnight in a dew chamber at $18^{\circ} \mathrm{C}$. The inoculated seedlings were then returned to the greenhouse $\left(18\right.$ to $\left.28^{\circ} \mathrm{C}\right)$. When uredinia appeared, the seedlings inoculated with each urediniospore sample were trimmed to leave one leaf with a single uredinium. Trimmed seedlings were placed in a dew chamber for 2 to $3 \mathrm{~h}$ to promote germination of urediniospores scattered on the leaf surface and then allowed to dry before the germinating urediniospores could reinfect the plants. Trimmed seedlings bearing single uredinia were then placed in polyethylene isolation cells in the greenhouse for several days to allow further sporulation in each isolated single uredinium. Urediniospores were then collected to establish one single-uredinial isolate per collection of rusted oat leaves. Each single-uredinial isolate was increased through one uredinial generation on 'Marvellous' oat seedlings in isolation cells.
Urediniospores of each single-uredinial isolate were collected and stored dry at $-50^{\circ} \mathrm{C}$ if not used in virulence tests within 2 weeks of collection. For shorter times, isolates were stored at $20 \%$ relative humidity at $4^{\circ} \mathrm{C}$.

Each isolate was tested for virulence on a set of 27 backcross lines of oat, each with a different single $P c$ gene for racespecific crown rust resistance (Table 1). Except for $P c-14$, the crown rust resistance genes in the differential set were derived from collections of wild oat, A. sterilis, from the Mediterranean region $(6,7,20$, 21,23). Pc-14 is from 'Ascencao', a Brazilian cultivar of $A$. sativa (18).

The differential lines were grown in vermiculite in $7-\mathrm{cm}$ square plastic pots with 10 to 20 seeds each of four lines planted in the four corners of each pot. At 7 to 10 days after planting, the seedlings in the differential set were inoculated with freshly collected urediniospores of a single-uredinial isolate suspended in lightweight mineral oil as described above. Inoculated plants were kept in a dew chamber overnight and then placed on a greenhouse bench. Disease reactions were evaluated on primary leaves at 12 to 15 days after inoculation. Responses with moderately large to large pustules with little or no chlorosis were scored as susceptible reactions; those with flecks or small pustules surrounded by chlorosis or necrosis were scored as resistant $(3,12)$.
Frequencies of virulence in the 1994 and 1998 collections from Uruguay, in the 1997, 1998, and 1999 collections from Brazil, and in the 1995 collection from Russia were compared with each other in all pair-wise combinations. For these comparisons, a similarity index (SI) was calculated for each pair based on absolute differences in virulence frequencies:

$$
\mathrm{SI}=\frac{1}{N} \sum_{i=1}^{N}\left|p_{i A}-p_{i B}\right|
$$

in which $N$ is the number of host lines in the differential set, $p_{i A}$ is the percent frequency of virulence on the $i$ th differential line in collection $\mathrm{A}$, and $p_{i B}$ is the percent frequency of virulence on the $i$ th differential line in collection B (12). Thus, collections with identical frequencies of virulence over all differential lines would have a value of $\mathrm{SI}=0.0$. Greater differences in virulence frequencies between pairs of collections indicate less similarity of virulence frequencies between them. To test for possible changes in virulence frequencies within crop years in Brazil, the isolates from each year in Brazil were divided into two sets of early and late isolates with approximately equal numbers of isolates in each set.

Mean virulence complexity values were determined for combined sets of collections from 1994 and 1998 from Uruguay, from 1997 to 1999 from Brazil, and for the 1995 collection from Russia. Virulence

Table 1. Frequencies of virulence $(\%)$ in isolates of Puccinia coronata from oat in Brazil and Uruguay compared with frequencies in isolates from Russia

\begin{tabular}{|c|c|c|c|c|c|c|c|c|}
\hline \multirow[b]{2}{*}{ Differential } & \multicolumn{4}{|c|}{ Brazil $^{\mathbf{a}}$} & \multicolumn{3}{|c|}{ Uruguay $^{b}$} & \multirow{2}{*}{$\frac{\text { Russia }^{c}}{1995}$} \\
\hline & 1997 & 1998 & 1999 & Ave. & 1994 & 1998 & Ave. & \\
\hline$P c-14$ & 87 & 86 & 86 & 87 & 62 & 87 & 78 & 94 \\
\hline$P c-35$ & 44 & 45 & 58 & 47 & 31 & 52 & 44 & 24 \\
\hline$P c-36$ & 55 & 64 & 60 & 60 & 23 & 61 & 47 & 35 \\
\hline Pc-38 & 7 & 34 & 45 & 27 & 77 & 30 & 47 & 47 \\
\hline Pc-39 & 78 & 38 & 68 & 60 & 54 & 57 & 56 & 35 \\
\hline$P c-40$ & 84 & 89 & 77 & 84 & 46 & 87 & 72 & 82 \\
\hline$P c-45$ & 91 & 18 & 42 & 51 & 38 & 35 & 36 & 18 \\
\hline$P c-46$ & 93 & 46 & 61 & 67 & 38 & 61 & 53 & 41 \\
\hline Pc- 48 & 60 & 21 & 32 & 38 & 31 & 22 & 25 & 0 \\
\hline$P c-50$ & 4 & 10 & 19 & 10 & 25 & 9 & 14 & 41 \\
\hline$P c-51$ & 47 & 45 & 61 & 49 & 23 & 48 & 39 & 63 \\
\hline$P c-52$ & 27 & 17 & 42 & 26 & 8 & 22 & 17 & 0 \\
\hline$P c-53$ & 41 & 2 & 6 & 17 & 31 & 9 & 17 & 0 \\
\hline$P c-54$ & 87 & 23 & 42 & 51 & 38 & 30 & 33 & 12 \\
\hline$P c-56$ & 47 & 66 & 71 & 60 & 23 & 74 & 56 & 44 \\
\hline$P c-57$ & 98 & 61 & 63 & 77 & 38 & 68 & 57 & 12 \\
\hline Pc-58 & 38 & 4 & 10 & 17 & 25 & 9 & 14 & 0 \\
\hline$P c-59$ & 23 & 39 & 45 & 34 & 46 & 26 & 33 & 13 \\
\hline$P c-60$ & 96 & 77 & 87 & 87 & 92 & 87 & 89 & 59 \\
\hline$P c-61$ & 92 & 64 & 65 & 75 & 54 & 74 & 67 & 35 \\
\hline$P c-62$ & 24 & 4 & 10 & 13 & 31 & 4 & 14 & 0 \\
\hline$P c-63$ & 7 & 27 & 32 & 21 & 62 & 26 & 39 & 24 \\
\hline$P c-64$ & 89 & 20 & 29 & 48 & 69 & 17 & 36 & 12 \\
\hline$P c-67$ & 93 & 36 & 35 & 57 & 62 & 65 & 64 & 18 \\
\hline Pc-68 & 0 & 2 & 0 & 1 & 15 & 0 & 6 & 18 \\
\hline Pc-70 & 36 & 40 & 68 & 46 & 42 & 50 & 47 & 38 \\
\hline $\mathrm{H} 546^{\mathrm{d}}$ & 73 & 7 & 32 & 38 & 38 & 17 & 25 & 0 \\
\hline No. isol. & 55 & 58 & 31 & 144 & 13 & 23 & 36 & 17 \\
\hline
\end{tabular}

\footnotetext{
a Isolates were collected mainly from Rio Grande do Sul; in 1997 and 1999 many isolates also were collected from Parana.

b Isolates were collected from Colonia.

c Isolates were collected from near Omsk and Altia in Siberia.

${ }^{\mathrm{d}}$ Line $\mathrm{H} 546$ has an unidentified gene for resistance to $P$. coronata.
} 
complexity was calculated as the mean number of virulences per isolate detected over the 27 differential lines. Mean virulence complexity values for Brazil, Uruguay, and Russia were also compared with mean virulence complexity over the same 27 differentials for isolates of $P$. coronata collected from Texas and in the northern plains states of Minnesota, North Dakota, and South Dakota of the United States. For these comparisons, virulence complexity values were calculated from data for the years 1995 to 1999 from the study reported by Leonard (12).

Races of $P$. coronata were determined as described by Chong et al. (3) for a standard North American set of 16 differential lines that comprised a subset of the 27 differentials used in this study. In addition, virulence associations were determined in $2 \times 2$ contingency tables for virulence on all possible paired combinations of differentials for isolates from each of the five collections of $P$. coronata from Brazil and Uruguay. For each pair of differentials, the number of isolates virulent to both, avirulent to both, virulent to the first but avirulent to the second, or avirulent to the first but virulent to the second were determined. Expected frequencies of isolates in each category were calculated as the product of the observed frequencies of isolates virulent or avirulent on each differential. For example, the expected frequency of isolates virulent on both differentials of the

Table 2. Frequencies of virulence (\%) in early ${ }^{\mathrm{a}}$ and late ${ }^{\mathrm{b}}$ collections of Puccinia coronata from oat in Brazil in 1998

\begin{tabular}{lcc}
\hline Differential & Early & Late \\
\hline$P c-14$ & 83 & 88 \\
$P c-35$ & 54 & 38 \\
$P c-36$ & 79 & 56 \\
$P c-38$ & 46 & 29 \\
$P c-39$ & 33 & 41 \\
$P c-40$ & 88 & 88 \\
$P c-45$ & 13 & 21 \\
$P c-46$ & 46 & 44 \\
$P c-48$ & 13 & 26 \\
$P c-50$ & 17 & 6 \\
$P c-51$ & 38 & 50 \\
$P c-52$ & 13 & 21 \\
$P c-53$ & 0 & 3 \\
$P c-54$ & 21 & 24 \\
$P c-56$ & 71 & 62 \\
$P c-57$ & 63 & 61 \\
$P c-58$ & 0 & 3 \\
$P c-59$ & 38 & 38 \\
$P c-60$ & 75 & 79 \\
$P c-61$ & 67 & 65 \\
$P c-62$ & 0 & 6 \\
$P c-63$ & 29 & 26 \\
$P c-64$ & 13 & 24 \\
$P c-67$ & 25 & 41 \\
$P c-68$ & 4 & 3 \\
$P c-70$ & 48 & 38 \\
H5 & 8 & 6 \\
No. isol. & 24 & 34 \\
\hline$C-16 c t 0 n$ & &
\end{tabular}

a Collections from 14 August to 11 September.

${ }^{\mathrm{b}}$ Collections from 24 September to 10 October.

${ }^{c}$ Line H546 has an unidentified gene for resistance to $P$. coronata. pair was determined by the product of the frequency of isolates in the population virulent on the first differential multiplied by the frequency of isolates virulent on the second differential. In positive associations, the numbers of isolates virulent on both differentials or avirulent on both differentials exceeded the expected values, whereas in negative associations, the number of isolates virulent on one differential but avirulent on the other exceeded the expected values. $P$ values for the statistical significance of the associations were calculated by Fisher's exact test (10).

\section{RESULTS}

Many (71\%) of the isolates from Brazil in 1998 were obtained from oat lines known to have single genes for racespecific resistance identical to those included in some of the lines in the differential set on which the isolates were tested. However, few isolates were obtained from lines with the same $P C$ gene. For example, three isolates each were obtained from lines with $P c-35, P c-40$, and $P c-64$, and no more than two isolates were obtained from lines with any of the other 20 known $P c$ genes in other lines from which collections were obtained. To avoid biasing the results based on source cultivars for the isolates, data from differential lines with the same resistance gene as that of the oat line on which the isolate was collected were omitted from calculations of mean virulence frequency for that year on that differential. Results of the adjusted virulence frequency values differed little from the unadjusted mean virulence frequencies (data not shown).

At least some virulence was found to each of the 27 crown rust differential oat lines in both Brazil and Uruguay, although only one isolate from Brazil (1\%) and two from Uruguay $(6 \%)$ were found with virulence to Pc-68 (Table 1). In some cases, the frequencies of virulence changed dramatically from year to year in the collections from Brazil. For example, virulence to $P c-45$ occurred at $91 \%$ in 1997 but just $18 \%$ in 1998; virulence to $P c-53$ occurred at $41 \%$ in 1997 and only $2 \%$ in 1998; and virulence to $P c-64$ occurred at $89 \%$ in 1997 and 20\% in 1998. Isolates from Russia were less virulent than those from Brazil and Uruguay on most differentials.
None of the isolates from Russia were virulent on $P c-48, P c-52, P c-53, P c-58$, or $P c-62$ or on line H546 (Table 1).

To determine whether virulence frequencies changed within years, the isolates from each year in Brazil were divided into approximately equal groups based on date of collection. Data from 1998, the year with the longest time between early and late collections, are shown in Table 2. Isolates from mid-August to mid-September differed little in virulence from those collected from late September to midOctober. In general, frequencies of virulence between early and late collections in 1998 were much more similar than frequencies of virulence between 1997 and 1998 (Tables 1 and 2). Isolates from early and late collections in 1997 and 1999 (data not shown) also had similar frequencies. This was true for the 1997 collection even though all of the early isolates in 1997 were from Rio Grande do Sul, and all but two of the late isolates in 1997 were from Parana and Santa Catarina to the north of Rio Grande do Sul.

A similarity index was calculated as the mean absolute difference in virulence frequency for each pair of collections of $P$. coronata isolates over all 27 lines in the differential set. Collections showing a high degree of similarity were Brazil 1998 and Uruguay 1998, Brazil 1999 and Uruguay 1998, and Brazil 1998 and Brazil 1999 (Table 3). The collection from Brazil in 1997 showed little similarity to any of the other collections. In general, the collection from Russia in 1995 showed little similarity in virulence frequencies to the collections from Brazil and Uruguay, although the Russian collection had virulence frequencies more similar to the Brazil 1998 collection than to other collections.

Virulence complexity of individual isolates of $P$. coronata from Brazil and Uruguay ranged from virulence to two $(7 \%)$ of the 27 differentials to 21 (75\%) (Fig. 1). Overall, $76 \%$ of the isolates were virulent on between 30 and $70 \%$ of the differentials. Mean virulence complexity was greater for isolates from Brazil and Uruguay than for isolates from Russia (Fig. 2). Mean virulence complexities were calculated also for isolates collected in 1995 to 1999 in Texas and the northern Great Plains states (MN, ND, SD) for compari-

Table 3. Average similarity of virulence frequencies ${ }^{\mathrm{a}}(\%)$ between collections of Puccinia coronata from Brazil in 1997 to 1999, Uruguay in 1994 and 1998, and Russia in 1995

\begin{tabular}{lccccc}
\hline & \multicolumn{5}{c}{ Region } \\
\cline { 2 - 5 } Region & Brazil 1997 & Brazil 1998 & Brazil 1999 & Uruguay 1994 & Uruguay 1998 \\
\hline Brazil 1998 & 28.1 & & & & \\
Brazil 1999 & 25.4 & 10.5 & & & \\
Uruguay 1994 & 29.3 & 22.7 & 19.9 & 22.2 & 20.1 \\
Uruguay 1998 & 22.7 & 7.5 & 8.7 & 25.4 & 20.9 \\
Russia 1995 & 38.1 & 14.5 & 20.9 & \\
\hline
\end{tabular}

a Average of the absolute value of the difference in virulence frequency between pairs of collections over 27 differential oat lines. 
son. As reported by Leonard (12), collections from Texas had significantly greater virulence complexity than isolates from the Northern Plains. The virulence complexity values calculated for these two regions of the United States were intermediate between those of Russia versus Brazil and Uruguay (Fig. 2).

Even though the sexual stage of $P$. coronata is assumed not to occur in South America because of the absence of aecial hosts, there was a great deal of diversity for virulence in the collections from Brazil and Uruguay. The ratio of number of races identified to isolates characterized with the standard set of 16 differentials of Chong et tions from Brazil and Uruguay and was 0.87 for the collection from Russia (Table 4). In 1998, the year with the greatest number of isolates from Brazil, there were 44 different races of $P$. coronata identified out of 58 isolates characterized.

Only 29 races of $P$. coronata were found more than once in the collections from Brazil and Uruguay (Table 5). The most frequent races were SJLM (six isolates), FBCG (five isolates), and NDQG (five isolates), which have little in common. Races SJLM, FBCG, and NDQG, as well as 11 other races, were found in more than one collection (country by year). Of these, five races were found both in Brazil 1998 and Uruguay 1998, three were found both in Brazil 1998 and Uruguay 1994, and one was found in both Brazil 1999 and Uruguay 1998. Only two races, KBBB and SJLT, found in Brazil 1997 were also found in Brazil 1998. No al. (3) ranged from 0.76 to 0.92 for collec-

race was found in both Brazil 1998 and Brazil 1999 (Table 5).

Tests of pair-wise combinations of virulence within collections of isolates showed that certain virulences were consistently associated in Brazil and Uruguay. Pairs of virulences that were significantly $(P<$ 0.05 ) associated in at least three of the five collections are shown in Table 6. No significant negative associations were common to more than two collections. With one possible exception, all of the significant positive associations common to at least three collections are consistent with virulence groups identified previously in collections of $P$. coronata from wild oat in Israel and cultivated oat in Texas and the Northern Plains of the United States (14). Virulence to $P c-53$ was not tested in the isolates of $P$. coronata from Israel, but it was significantly associated with virulence to $P c-58$ in the Northern Plains but not in Texas. The other virulence groups listed in Table 6 represent associations that were common to both regions of the United States and to Israel. Associations of virulence to $P c-38$ and $P c-63$ and to $P c-48$ and $P c-52$ have been reported also in Canada (4).

The single year of collection of $P$. coronata from Russia and the small number of isolates in that collection make it difficult to draw conclusions from the 20 significantly positive and three negative associations that were observed for the Russian isolates. Eight of the 20 significant positive associations were consistent with virulence groups previously identified in the United States and Israel. These were $P c-35$ with

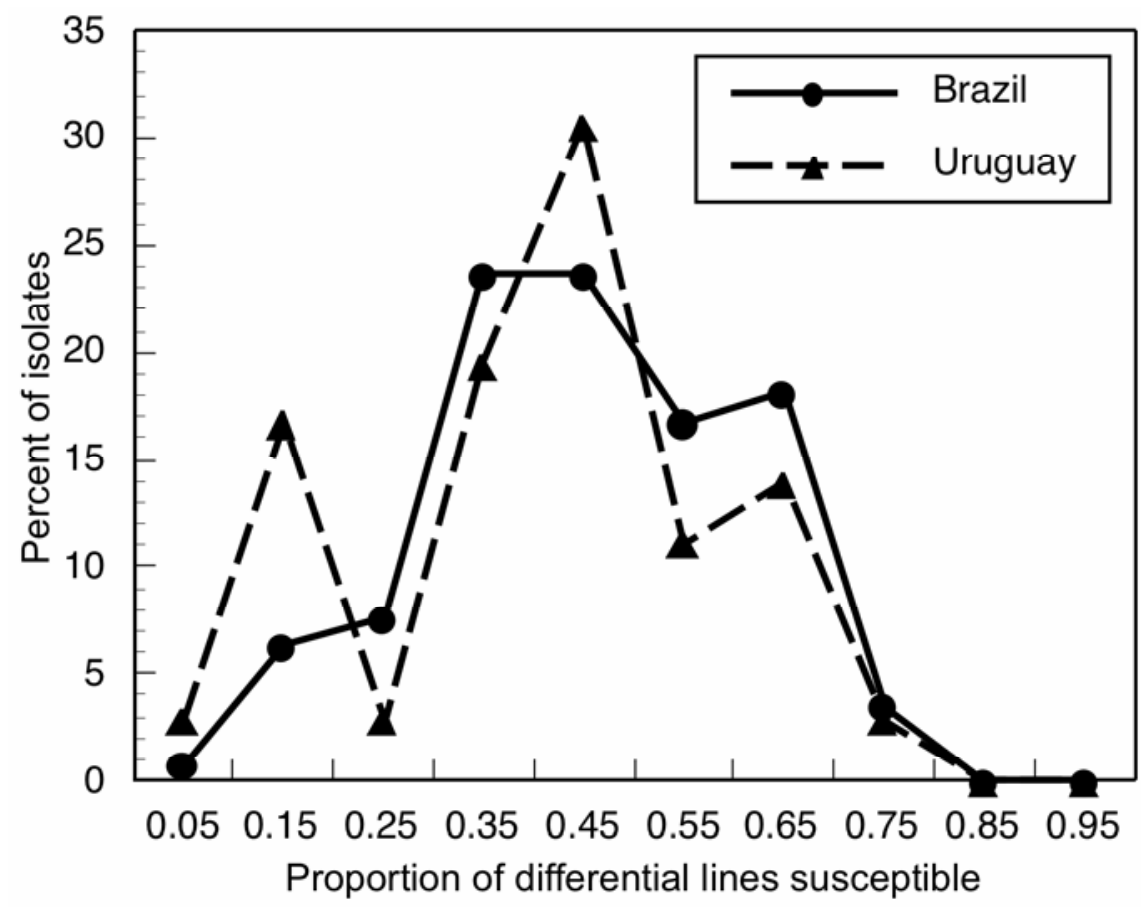

Fig. 1. Distribution of virulence complexity among isolates of Puccinia coronata from oat in Brazil and Uruguay. Complexity is expressed as the percentage of differentials to which each isolate was virulent out of a set of 27 lines, each with a different gene for race-specific resistance. Collections were from 1997 to 1999 in Brazil and 1994-95 and 1998 in Uruguay.
$P c-59$ and $P c-70 ; P c-38$ with $P c-39, P c-$ 63 , and $P c-70 ; P c-45$ with $P c-57$; and $P c$ 61 with $P c-51$ and $P c-60$.

\section{DISCUSSION}

Even though there is no evidence for sexual reproduction by $P$. coronata in South America, the P. coronata populations in Brazil and Uruguay exhibit a great deal of diversity for virulence as indicated by the large number of races identified. Most of the races were found only once in the 4 years of the survey, and the most common race occurred at a frequency of less than $4 \%$ of the total isolates.

Even though the 27 oat crown rust differential lines used in this study were selected for their usefulness in differentiating virulence diversity of $P$. coronata in North America rather than in South America, the $P$. coronata populations in Brazil and Uruguay were polymorphic for virulenceavirulence to every one of the 27 differentials. Such a high level of genetic diversity suggests either that the polymorphisms are maintained by some form of balancing selection or that genetic drift has little or no influence on the pathogen populations there. In populations of small size or in populations that periodically suffer crashes

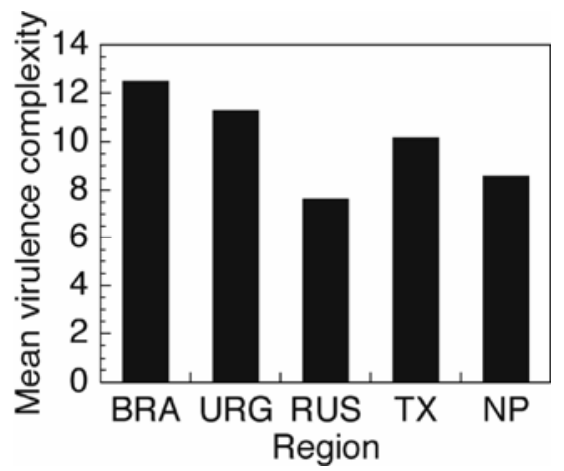

Fig. 2. Average virulence complexity of isolates of Puccinia coronata from Brazil and Uruguay compared with isolates from western Siberia (Russia) and from Texas and the Northern Plains of the United States. Values for the United States were calculated for collections from 1995 to 1999 reported by Leonard (12). Isolates from Brazil were collected in 1997 to 1999; isolates from Uruguay were collected in 1994-95 and 1998; and isolates from Russia were collected in 1995.

Table 4. Numbers of races of Puccinia coronata identified in collections from oat in Brazil, Uruguay, and Russia

\begin{tabular}{lcc}
\hline Collection & No. isolates $^{\mathbf{a}}$ & No. races \\
\hline Brazil 1997 & 53 & 41 \\
Brazil 1998 & 58 & 44 \\
Brazil 1999 & 30 & 27 \\
Uruguay 1994 & 13 & 12 \\
Uruguay 1998 & 23 & 20 \\
Russia 1995 & 15 & 13 \\
\hline
\end{tabular}

a Two isolates in Brazil 1997, one in Brazil 1999, and two in Russia 1995 could not be classified by race because of missing data for one key differential. 
and undergo bottleneck conditions, genetic diversity tends to be lost by genetic drift when rare alleles are eliminated and very common alleles become fixed by chance. The relative unimportance of genetic drift in South American populations of P. coronata can be attributed to the presence of oat and oat crown rust throughout the year in southern Brazil and in Uruguay and Argentina. During the interval between successive oat crops, November to March in southern Brazil and January to March in Argentina and Uruguay, volunteer oat plants are abundant and heavily infected with crown rust because of the mild, humid summer weather. Thus, there is a green bridge that prevents seasonal population crashes of $P$. coronata in the oat growing region of southern Brazil, Uruguay, and northern Argentina. This should allow random mutations to accumulate in the population and may account for the observed high level of polymorphism even though the population is asexual.

Among the 27 different genes for racespecific resistance represented in the differential lines used in this study, only $P c$ 68 appears to have some potential value for use in breeding for crown rust resistance in Brazil or Uruguay. Only three isolates from the survey were virulent on $P c-68$. The presence of these virulent isolates warrants caution in the use of $P c-68$, but $P c-68$ may provide some protection if it is not used too extensively. It is worth noting that a recent survey of $P$. coronata virulence showed no detectable virulence to $P c-68$ among isolates collected from wild A. sterilis in Israel (13). In recent years, oat cultivars with $P c-68$ have been released in Manitoba, but for now, at least, the frequency of virulence to $P c-68$ remains low $(4,12)$. In the long run, however, it seems advisable to put more emphasis on breeding oat cultivars for higher levels of nonspecific slow rusting resistance.

The moderate to high frequencies of virulence to the other 26 differential lines used in this study are surprising. With the exception of $P c-14$, all of the resistance genes were derived from accessions of $A$. sterilis collected in the Mediterranean region (mostly Israel) in the 1960s and 1970s. These accessions were utilized first by oat breeders in Canada and the United States. Thus, oat lines bearing $P c$ genes introgressed from those A. sterilis accessions could not have been present in South America for more than 30 or 40 years. The genes most likely to have been introduced into South American oat cultivars are $P c$ 58, $P c-59, P c-60$, and $P c-61$. These four genes are in oat cultivars from Texas A\&M University and Coker Seed Company that are included in the Quaker Oat International Nursery, which has been grown for many years in several South American countries. Most of the other genes of the 27 differentials (with the exception of $P c$ 38, $P c-39, P c-48$, and $P c-68)$ have either not been used at all in commercial production in North America or were used only in oat multiline cultivars developed and grown in Iowa. It seems unlikely that many of these genes have been used in oat breeding in South America. Still, moderate to high levels of virulence to these genes, other than $P c-68$, already exist in the South American populations of $P$. coronata.

There is another puzzling aspect to genetic diversity for virulence in the $P$. coronata populations of Brazil and Uruguay. Frequencies of virulence on many of the differential lines differed widely between the 1997 and 1998 collections of P. coronata in Brazil. This seems inconsistent with the similarity of virulence frequencies between the 1998 collection from Uruguay and the 1998 and 1999 collections from Brazil. In 1998 and 1999, all or nearly all of the Brazilian isolates came from the state of Rio Grande do Sul, whereas in 1997 approximately half of the isolates (those collected on 11 September or later) came from the states of Parana and Santa Catarina to the north of Rio Grande do Sul. However, the similarity index for these two groups of isolates from 1997 was 8.4, which indicates greater similarity than that between the 1998 and 1999 collections from Brazil. Thus, we found no evidence of distinct geographically separated populations of $P$. coronata within the states of southern Brazil. On the other hand, there is no reason to think that the marked differences in virulence frequencies between the 1997 collection in Brazil and those in the 1998 and 1999 collections were due to selection for virulence. In fact, the average virulence complexity of the 1997 isolates was slightly greater than that of the 1998 and 1999 isolates.

Earlier studies in the United States showed that mean virulence complexity in

Table 5. Races of Puccinia coronata found more than once in Brazil and Uruguay in 1994 to 1999

\begin{tabular}{|c|c|c|c|c|c|c|}
\hline \multirow[b]{2}{*}{ Race } & \multicolumn{6}{|c|}{ Number of isolates of indicated race } \\
\hline & Brazil-97 & Brazil-98 & Brazil-99 & Urug.-94 & Urug.-98 & Total \\
\hline BLBC & 0 & 0 & 0 & 2 & 0 & 2 \\
\hline FBCG & 0 & 2 & 0 & 0 & 3 & 5 \\
\hline JJNH & 2 & 0 & 0 & 0 & 0 & 2 \\
\hline KBBB & 1 & 1 & 0 & 0 & 0 & 2 \\
\hline LBBG & 0 & 3 & 0 & 0 & 0 & 3 \\
\hline LBCG & 0 & 3 & 0 & 0 & 0 & 3 \\
\hline LBLG & 0 & 0 & 2 & 0 & 0 & 2 \\
\hline LGLB & 0 & 0 & 0 & 0 & 2 & 2 \\
\hline LGMB & 0 & 2 & 0 & 0 & 0 & 2 \\
\hline LQBB & 2 & 0 & 0 & 0 & 0 & 2 \\
\hline LQBC & 0 & 2 & 0 & 1 & 0 & 3 \\
\hline LQLG & 0 & 1 & 0 & 0 & 1 & 2 \\
\hline LQLQ & 0 & 1 & 0 & 1 & 0 & 2 \\
\hline MBMG & 0 & 1 & 0 & 1 & 0 & 2 \\
\hline MMLB & 0 & 1 & 0 & 1 & 0 & 2 \\
\hline NBMG & 0 & 1 & 0 & 0 & 1 & 2 \\
\hline NDQG & 0 & 3 & 0 & 0 & 2 & 5 \\
\hline NJQG & 0 & 2 & 0 & 0 & 0 & 2 \\
\hline NLMG & 0 & 3 & 0 & 0 & 0 & 3 \\
\hline NQBG & 0 & 0 & 1 & 0 & 1 & 2 \\
\hline QBBB & 0 & 1 & 0 & 0 & 1 & 2 \\
\hline SBBT & 1 & 0 & 1 & 0 & 0 & 2 \\
\hline SBCR & 2 & 0 & 0 & 0 & 0 & 2 \\
\hline SGDR & 2 & 0 & 0 & 0 & 0 & 2 \\
\hline SJLL & 0 & 0 & 3 & 0 & 0 & 3 \\
\hline SJLM & 5 & 0 & 1 & 0 & 0 & 6 \\
\hline SJLT & 1 & 1 & 0 & 0 & 0 & 2 \\
\hline SJQB & 3 & 0 & 0 & 0 & 0 & 3 \\
\hline SQBR & 0 & 0 & 0 & 0 & 2 & 2 \\
\hline
\end{tabular}


$P$. coronata was significantly greater in isolates from California and the southern states from Texas to Virginia than in the northern Great Plains states of Minnesota, North Dakota, and South Dakota (12). This was true even when considering only those virulences for which there was no evidence of directional selection over the period of 1990 to 2000. This trend of greater virulence complexity in $P$. coronata populations in regions of warmer climates is confirmed by the high virulence complexity in Brazil and Uruguay. Virulence complexity values for both Brazil and Uruguay were greater than for any region of the United States. Conversely, the mean virulence complexity for the $P$. coronata isolates collected from western Siberia in Russia in 1995 was lower than that of the northern Great Plains of the United States. The reason for this apparent association of greater virulence in warmer climates is not clear. Leonard (12) pointed out that virulence to $P c-45, P c-46$, and $P c-54$ all occurred at relatively high frequencies in California and in countries of southern Europe but at low frequencies in northern Europe and in the northern United States. Virulence to $P c-45, P c-46$, and $P c-54$ also occurred at relatively high frequencies in Brazil and Uruguay. In Russia, the frequencies of virulence to $P c-45$ and $P c-54$ were low, but the frequency of virulence to $P c-46$ was relatively high, unlike the lower frequency of this virulence in the northern United States.

Table 6. Statistically significant ${ }^{\mathrm{a}}$ pair-wise virulence associations observed consistently in Puccinia coronata collections from Brazil (1997, 1998, 1999) and Uruguay $(1994,1998)$

\begin{tabular}{|c|c|c|}
\hline $\begin{array}{l}\text { Virulence } \\
\text { pair }^{\text {b }}\end{array}$ & $\begin{array}{c}\text { No. samples } \\
\text { significant }\end{array}$ & $\begin{array}{c}\text { Virulence } \\
\text { group }^{\mathbf{c}}\end{array}$ \\
\hline$P c-36, P c-56$ & 5 of 5 & 61 \\
\hline Pc-38, Pc-63 & 5 of 5 & 38 \\
\hline$P c-39, P c-70$ & 5 of 5 & 38 \\
\hline$P c-45, P c-54$ & 5 of 5 & 45 \\
\hline$P c-46, P c-48$ & 4 of 5 & 45 \\
\hline$P c-46, P c-57$ & 4 of 5 & 45 \\
\hline$P c-53, P c-58$ & 4 of 5 & $58 ?^{\mathrm{d}}$ \\
\hline$P c-45, P c-46$ & 3 of 5 & 45 \\
\hline$P c-46, P c-54$ & 3 of 5 & 45 \\
\hline$P c-48, P c-52$ & 3 of 5 & 45 \\
\hline
\end{tabular}

a Significant at $P<0.05$, determined by Fisher's exact test.

${ }^{\mathrm{b}}$ Only pairs that were significantly associated in at least three of five collections are shown.

c Four virulence groups determined from consistent associations in collections of $P$. coronata from wild oat in Israel and from cultivated oat in Texas and the Northern Plains (MN, ND, SD) of the United States: virulence to $P c 38$, 39, 63, 70 (Group 38), to $P c-45,46,48,52,54$ (Group 45), to $P c-35,40,58,59$ (Group 58), and to $P c-36,51,56,60,61$ (Group 61) (14).

d Virulence to $P c-53$ was significantly associated with Group 58 in collections from the Northern Plains but not in collections from Texas; virulence to $P c-53$ was not tested for collections from Israel (14).
Ten pairs of virulences were found to be significantly associated in at least three of the five collections from Brazil and Uruguay even though the total diversity of races in these collections was great and few races were found to recur in successive years. Of the 10 pairs of associated virulences, nine were consistent with three of the four groups of associated virulences previously identified consistently in collections from Israel, Texas, and the northern Great Plains of the United States. The tenth pair of virulences that were significantly associated, virulence to $P c-53$ and $P c-58$, was consistent with an association of virulence to $P c-53$ with virulence group 58 in collections of $P$. coronata from the northern Great Plains of the United States. Virulence to $P c-53$ was not tested in the isolates from Israel and was not significantly associated with virulence to $P c-58$ in Texas (14).

The reasons for the high level of virulence polymorphism in $P$. coronata are not clear. Polymorphism in natural $P$. coronata populations on wild $A$. sterilis might be the result of long-term coevolution of host and pathogen, leading to equilibria between frequencies of resistance genes in the host and virulence genes in the pathogen as modeled by Leonard (11). In the northern United States, selection of $P$. coronata genotypes heterozygous for virulence and avirulence in combination with genetic recombination each year on the aecial host might contribute to maintenance of polymorphisms in those populations of $P$. coronata. Kolmer (8) reported selection for virulence-avirulence heterozygotes in wheat leaf rust, Puccinia triticina $(=P$. recondita $\mathrm{f}$. sp. tritici). Selection for heterozygotes, however, cannot explain the high level of polymorphism in populations of $P$. coronata in South America. The absence of aecial hosts in South America rules out the possibility of annual cycles of genetic recombination in sexual reproduction by $P$. coronata, which could regenerate diversity following selection of heterozygotes. Also, coevolution cannot explain the maintenance of polymorphisms in $P$. coronata in South America. Cultivated oat, the predominant host for $P$. coronata in Brazil and Uruguay, is not free to respond directly to selection resulting from changes in virulence in the pathogen population as populations of A. sterilis apparently do in Israel. Therefore, coevolution does not proceed by naturally selected adjustments in the host population in Brazil or Uruguay in response to changes due to natural selection in the pathogen population. It appears, therefore, that some form of balancing selection may operate in populations of $P$. coronata to favor intermediate levels of virulence complexity as suggested by Kolmer (9) for $P$. triticina, the wheat leaf rust fungus.

Leonard (12) suggested that balancing selection for intermediate levels of viru- lence complexity might account for the high levels of polymorphism observed in the southern United States, where the aecial stage of $P$. coronata is rare or absent. Leonard (12) also suggested that such balancing selection may be environmentally sensitive, with higher levels of virulence being favored in warmer climates. The high levels of virulence complexity in collections of $P$. coronata from Brazil and Uruguay are consistent with this hypothesis.

If balancing selection for intermediate levels of virulence complexity does occur in $P$. coronata, it may not be entirely random with respect to which virulences are selected, even on susceptible hosts. Evidence that pairs of virulences within each of four virulence groups consistently show significant associations was found not only in the United States and Israel (14), but also in this study in Brazil and Uruguay. This tendency for virulences within each group to occur together might result in a tendency for the proposed balancing selection to cause certain blocks of virulence genes to increase in frequency and other blocks to decrease in response to changes in the host population.

The stabilizing selection observed by Bardin and Leonard (1) for a heterogeneous population of $P$. coronata derived from the buckthorn nursery in St. Paul, MN, and maintained on susceptible oat seedlings in the greenhouse is not necessarily inconsistent with the hypothesis of balancing selection favoring intermediate virulence complexity. Oat lines with a wide variety of $P c$ genes for crown rust resistance have been grown in the St. Paul, MN, buckthorn nursery for more than 40 years. Selection within the population of $P$. coronata in the buckthorn nursery during that time should have resulted in a higher level of virulence complexity than would have been favored on a host population without race-specific resistance. Thus, the reduction in virulence observed in the greenhouse by Bardin and Leonard (1) over successive generations of the $P$. coronata population on seedlings of a susceptible oat cultivar could have been partly due to selection for a lower optimal level of mean virulence complexity in their greenhouse population of $P$. coronata compared with the parent field population. Further analysis of the data of Bardin and Leonard (1) seems warranted to determine whether the proportions of isolates with both high and low virulence complexity decreased in their population during 10 uredinial generations of culture on susceptible oat seedlings in the greenhouse.

\section{ACKNOWLEDGMENTS}

N. Altier, S. Pureyra, and M. Rebuffo are gratefully acknowledged for providing collections of oat crown rust from Uruguay, as is J. Holland for providing the isolates from Siberia. We also gratefully acknowledge the excellent technical assistance of G. E. Ochocki in establishing and testing singleuredinial isolates of $P$. coronata. 


\section{LITERATURE CITED}

1. Bardin, M., and Leonard, K. J. 2000. Selection against unnecessary virulence in Puccinia coronata. Acta Phytopathol. Entomol. Hung. 35:223-227.

2. Chaves, M. S., Martinelli, J. A., and Federizzi, L. C. 2004. Resistência quantitativa à ferrugem da folha em genótipos de aveia branca: III Correlação de componentes de resistência entre si e com a intensidade de doença no campo. Fitopatol. Bras. 29:197-200.

3. Chong, J., Leonard, K. J., and Salmeron, J. J. 2000. A North American system of nomenclature for Puccinia coronata f. sp. avenae. Plant Dis. 84:580-585.

4. Chong, J., and Zegeye, T. 2004. Physiologic specialization of Puccinia coronata f. sp. avenae, the cause of oat crown rust, in Canada from 1999 to 2001. Can. J. Plant Pathol. 26:97-108.

5. Federizzi, L. C., and Stuthman, D. 1998. Por que genes maiores para a resistência à ferrugem da folha têm pouca durabilidade no Brasil. In: Reuniäo da Comissäo Brasileira de Pesquisa de Aveia (18:1998. Londrina). Resultados experimentais. IAPAR, 1998.

6. Fleischmann, G., and Baker, R. J. 1971. Oat crown rust race differentiation: Replacement of the standard differential varieties with a new set of single resistance gene lines derived from Avena sterilis. Can. J. Bot. 49:1433-1437.

7. Harder, D. E., McKenzie, R. I. H., and Martens, J. W. 1980. Inheritance of crown rust resistance in three accessions of Avena sterilis. Can. J. Genet. Cytol. 22:27-33.
8. Kolmer, J. A. 1992. Virulence heterozygosity and gametic phase disequilibrium in two populations of Puccinia recondita (wheat leaf rust fungus). Heredity 68:505-513.

9. Kolmer, J. A. 1994. Selection of Puccinia recondita $\mathrm{f}$. $\mathrm{sp}$. tritici virulence phenotypes in three multilines of Thatcher wheat lines near isogenic for leaf rust resistance genes. Can. J. Bot. 73:1081-1088.

10. Langsrud, Ø. 1999. Fisher's exact test. Statistics and Chemometrics at Matforsk website.

11. Leonard, K. J. 1997. Modeling gene frequency dynamics. Pages 211-230 in: The Gene-forGene Relationship in Host-Parasite Interactions. I. A. Crute, J. J. Burdon, and E. B. Holum, eds. CAB International, Wallingford, UK.

12. Leonard, K. J. 2003. Regional frequencies of virulence in oat crown rust in the United States from 1990 through 2000. Plant Dis. 87:13011310 .

13. Leonard, K. J., Anikster, Y., and Manisterski, J. 2004. Patterns of virulence in natural populations of Puccinia coronata on wild oat in Israel and in agricultural populations on cultivated oat in the United States. Phytopathology 94:505-514.

14. Leonard, K. J., Anikster, Y., and Manisterski, J. 2005. Virulence associations in oat crown rust. Phytopathology 95:53-61.

15. Martinelli, J. A. 2000. Major diseases on oats in South America. Pages 277-283 in: Proc.VI International Oat Conference, Canterburry, New Zealand, 2000.

16. Martinelli, J. A., Federizzi, L. C., and Benedetti, A. C. 1994. Redução no rendimento de grãos de aveia em função da severidade da ferrugem da folha. Sum. Phytopathol. 40:116118.

17. Matzenbacher, R. G. 1999. A Cultura da Aveia no Sistema de Plantio Direto. Cruz Alta: Fundacep-Fecotrigo.

18. Michel, L. J., and Simons, M. D. 1985. Registration of oat germplasms IA H676, IA H677, and IA H681 resistant to the oat crown rust fungus. Crop Sci. 25:716-717.

19. Rebuffo, M. 1997. Oat use and production in Uruguay. Pages 25-28 in: Proc. South American Oats Congress, 3rd. INIA La Estanzuela, Colonia, Uruguay, November 11-12, 1997.

20. Roelfs, A. P., Hughes, M. E., and Long, D. L. 2003. Catalog of Rust Resistance Genes in Small Grains. U.S. Dep. Agric. Agric. Res. Serv., Cereal Disease Lab. Online publication CDL-EP\#005. Updated annually.

21. Simons, M. D., Martens, J. W., McKenzie, R. I. H., Nishiyama, I., Sadanaga, K., Sebesta, J., and Thomas, H. 1978. Oats: A standardized system of nomenclature for genes and chromosomes and catalog of genes governing characters. U.S. Dep. Agric. Agric. Handb. no. 509.

22. Trombetta, R. V. 1997. Oats situation in Argentina. Pages 15-16 in: Proc. South American Oats Congress, 3rd. INIA La Estanzuela, Colonia, Uruguay, November 11-12, 1997.

23. Wong, L. S. L., McKenzie, R. I. H., Harder, D. E., and Martens, J. W. 1983. The inheritance of resistance to Puccinia coronata and of floret characters in Avena sterilis. Can. J. Genet. Cytol. 25:329-335. 